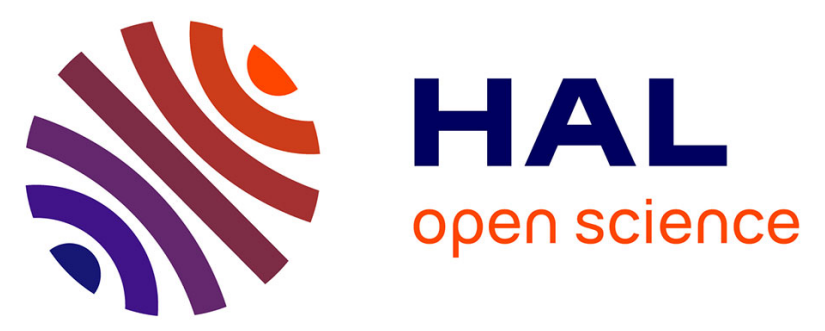

\title{
THE DISLOCATION-ENHACED SNOEK EFFECT (DESE) IN HIGH PURITY IRON DOPED WITH DIFFERENT AMOUNTS OF CARBON
}

J. Rubianes, L. Magalas, Gilbert Fantozzi, J. San Juan

\section{- To cite this version:}

J. Rubianes, L. Magalas, Gilbert Fantozzi, J. San Juan. THE DISLOCATION-ENHACED SNOEK EFFECT (DESE) IN HIGH PURITY IRON DOPED WITH DIFFERENT AMOUNTS OF CARBON. Journal de Physique Colloques, 1987, 48 (C8), pp.C8-185-C8-190. 10.1051/jphyscol:1987825 . jpa-00227129

\section{HAL Id: jpa-00227129 \\ https://hal.science/jpa-00227129}

Submitted on 1 Jan 1987

HAL is a multi-disciplinary open access archive for the deposit and dissemination of scientific research documents, whether they are published or not. The documents may come from teaching and research institutions in France or abroad, or from public or private research centers.
L'archive ouverte pluridisciplinaire HAL, est destinée au dépôt et à la diffusion de documents scientifiques de niveau recherche, publiés ou non, émanant des établissements d'enseignement et de recherche français ou étrangers, des laboratoires publics ou privés. 


\title{
THE DISLOCATION-ENHANCED SNOEK EFFECT (DESE) IN HIGH PURITY IRON DOPED WITH DIFFERENT AMOUNTS OF CARBON
}

\author{
J. RUBIANES, L.B. MAGALAS ${ }^{(1)}$, G. FANTOZZI and J. SAN JUAN* \\ Groupe d'Etudes de Métallurgie Physique et de Physique des \\ Matériaux (UA 341) INSA de Lyon, Bât. 502, F-69621 Villeurbanne \\ Cedex, France \\ "Dpto de Física del Estado sólido, Facultad de Ciencias, \\ Universidad del pais Vasco, Aptdo 644, SP-48009 Bilbao, Spain
}

\begin{abstract}
Resumé - On a étudié systèmatiquement l'influence de la déformation plastique et du recuit à basse température dans le Dislocation-Enhanced Snoek Effect dû au carbone $\mathrm{DESE} / \mathrm{C} /$, dans le fer de haute pureté contenant différentes concentrations de carbone. On montre, d'après les resultats expérimentaux, que le pic snoek dû au carbone se transforme dans le DESE/C/ après déformation plastique à température ambiante. Les deux phénomènes ont lieu à la même température. On montre l'influence de la déformation plastique, de la concentration de carbone en solution solide et. des précipités dans le DESE/C/ dû au carbone dans le fer déformé.
\end{abstract}

\begin{abstract}
A systematic study of the influence of plastic deformation and low temperature annealing on the carbon Dislocation-Enhanced Snoek Effect (DESE/C/) in high purity iron containing different carbon concentrations is reported. It is proved according to the experimental observations that after plastic deformation at room temperature the carbon snoek effect is being transformed into the carbon DESE/C/ and both phenomena occur at the same temperature. The influence of plastic deformation, carbon concentration in solid solution and carbon precipitations on the carbon DESE/C/ in deformed iron is reported.
\end{abstract}

\section{INTRODUCTION}

The Snoek effect is a well known point defect relaxation in bec metals (6). As pointed out in the previous papers $(1,4,7)$, the Snoek peak can be transformed under appropriate conditions of plastic deformation into the Dislocation-Enhanced Snoek Peak (DESP), which occurs at nearly the same temperature as the Snoek peak. To summarize the work on the DESE in high purity $\mathrm{Fe}-\mathrm{C}, \mathrm{Fe}-\mathrm{N}$ alloys, and in Fe-C-N Armeo iron of technical purity, it can be said that a good deal of evidence can be fitted together to support the claim that the carbon and nitrogen $\mathrm{DESE} / \mathrm{C}, \mathrm{N} /$ in $\alpha-\mathrm{Fe}$ is connected with the movement of non-screw $\left(71^{\circ}\right)$ dislocations, which is controlled by the carbon or/and nitrogen snoek-type point defect relaxation. It should be pointed out, that although the Snoek peak and the corresponding DESP occur at the same temperature, and the activation parameters of the DESE are very similar to those of the snoek effect the DESP is no longer a point defect relaxation.

According to Magalas $(1,4,7)$, the salient features of the DESE in iron are:

i.) The DESP/C,N/ occurs in freshly deformed iron, provided dynamic strain ageing at room temperature (RT) is eliminated by fast cooling from RT to $77 \mathrm{~K}$.

ii.) The DESP/C,N/ occurs at the same temperature as the corresponding Snoek peak.

iil.) The relaxation strength of the DESP/C,N/ is proportional to the amount of plastic deformation at RT. Thus the relaxation mechanism responsible for the DESE must involve the movement of dislocations.

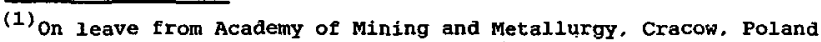


iv.) The DESP/C,N/ shows a lognormal distribution of the relaxation times; the DESP/C,N/ Is essentially broader than the single Debye peak.

v.) The enhancement of the carbon or nitrogen Snoek peak due to plastic deformation is stronger for lower concentrations of foreign interstitial atoms (FIAs).

vi.) The $D E S E / C, N /$ is a metastable relaxation. The thermal instability of the $\mathrm{DESE} / \mathrm{C}, \mathrm{N} /$ is due to dislocation pinning by FIAs $(\mathrm{C}, \mathrm{N})$.

The foregoing paper aims at evidencing of the occurence of the carbon DESE/C/ in high purity iron doped with different concentrations of carbon. The evolution of the carbon DESP/C/ during low temperature annealing is also reported. Finally, an attempt is undertaken to confirm the existence of the carbon DESE/C/ in iron doped with high concentration of carbon (1000 at. ppm), which is the less favorable condition to observe the DESE/C/. The experimental results obtained in this study are in agreement with the results of Magalas et al. $(1,4,7)$ and corroborate the presence of a strong, anelastio relaxation referred to here as the carbon Dislocation-Enhanced Snoek Effect - DESE/C/.

\section{EXPERIMENTAL METHOD}

Experiments were made with high purity iron doped with different carbon concentrations. The sample preparation of the CEN.Grenoble iron doped with 1000 or $50 \mathrm{ppm}$ of carbon is described elsewhere (5). Regarding the concentration of carbon interstitial atoms, the samples are referred to as A for $1000 \mathrm{ppm}$, and $B$ for 50 ppm.The specimens ( $1 \mathrm{~mm}$ diameter, $50 \mathrm{~mm}$ length) were saturated from $720^{\circ} \mathrm{C}$ (under argon atmosphere) into cold water. After the saturation treatment, the superficial oxide layer was removed by chemical polishing and the samples were stored in liquid nitrogen. The carbon concentration in solid solution as estimated from the height of the carbon Snoek peak was: $680 \mathrm{ppm}$ for sample A, and $25 \mathrm{ppm}$ for sample $\mathrm{B}$.

The internal friction (IF) and shear modulus $\left(G \approx f^{2}\right)$ were measured in an inverted torsion pendulum, oscillating near $1 \mathrm{~Hz}$, as a function of temperature with a controlled heating or cooling rate of $100 \mathrm{~K} / \mathrm{h}$ in the presence of a magnetic field of 200 0e. The maximum shear strain amplitude was $1 \cdot 10^{-5}$. After cold work (CW) at RT by torsion inside the pendulum the samples were immediately cooled down to $77 \mathrm{~K}$.

\section{RESULTS}

Experiments have been carried out in order to study the effect of plastic deformation on the carbon Snoek relaxation in iron. The IF and shear modulus were measured as a function of temperature from $150 \mathrm{~K}$ to $400 \mathrm{~K}$. The transformation of the carbon Snoek peak into the carbon DESP/C/ will be demonstrated in iron doped with high (Fig.1) or low (Fig.2) concentrations of carbon.

3.1. The carbon DESE/C/ in iron doped with $1000 \mathrm{ppm}$ of carbon.

The initial carbon Snoek peak obtalned after the saturation treatment is shown in Fig.1, curve 1,1' for sample A. The Snoek effect is accompanied by a modulus defect, curve 1'. In freshly saturated iron, from the temperature of the maximum carbon solid solubility, an ageing effect at room temperature is an inevitable process. In fact, dislocation pinning can be observed in the modulus curve starting from the carbon Snoek peak temperature (curve 1'). It Is important to outline that plastic deformation at RT was carried out after the first IF measurement of the carbon Snoek peak, i.e., the sample had been annealed at $400 \mathrm{~K}$ before the first $\mathrm{CW}$ took place. After $14 \% \mathrm{CW}$ at RT one can observe the carbon $\mathrm{DESP} / \mathrm{C} /$ at nearly the same temperature as the carbon snoek peak (curve 2). In addition, the DESP/C/ is substantially wider in comparison with the carbon Snoek peak. Thus, the $\beta$ parameter of the lognormal distribution of the relaxation times for the carbon DESP/C/ is $\beta \simeq 4$.

The carbon DESP/C/ detected in the IF experiments is accompanied by continuous dislocation pinning, which starts here as $10 \mathrm{w}$ as $260 \mathrm{~K}$, curve $2^{\prime}$. Hence the dislocation pinning is responsible for the asymetry of the DESP/C/ and also causes thermal instability of the DESE/C/ in 1ron. Finally, the DESP/C/ disappears after annealing at $690 \mathrm{~K}$, curve 3. The influence of the amount of torsional plastic deformation at RT on the height of the carbon DESP/C/ obtained after background subtraction is shown in Fig.4, curve 1 . 
3.2 The carbon DESE/C/ in iron doped with $50 \mathrm{ppm}$ of carbon.

Similar experimental procedure and IF experiments have been carried out with sample B. Thus, the behaviour of the carbon DESP/C/ can be directly compared in the case of deformed iron doped with high or low carbon concentrations, i.e., containing relatively high or low concentrations of carbon atoms in solid solution. A typical example of the carbon DESP/C/ in Iron doped with low concentrations of carbon is shown in Fig. 2 after $10 \% \mathrm{CW}$ at RT (curve 2,2'). The DESP/C/ is influenced by the carbon Snoek-Köster relaxation which occurs here around $545 \mathrm{~K}$. In a similar way, as in iron doped with high carbon concentrations, dislocation pinning is responsible for the thermal instability of the DESP/C/. In this case, however, dislocation pinning can be noticed at lower temperatures (see Fig.2, curve 2'). The influence of the amount of plastic deformation at RT on the height of the DESP/C/ is shown in Fig.4, curve 2. The evolution of the IF and shear modulus after $10 \% \mathrm{CW}$ at RT is show in Fig. 3 as a function of successive annealings at $305 \mathrm{k}$.

\subsection{The carbon DESE/C/ in $\alpha-\mathrm{Fe}$.}

It is confirmed that the carbon DESE/C/ can be observed in low or high carbon-concentration doped iron (Fig.1,2,3). In general, the height of the DESP/C/ depends on the amount of plastic deformation. It can be noticed, however, that the height of the DESP/C/ can reach a saturation level as shown in Fig.4, curve 1,2,4. It seems that the DESP/C/ in iron doped with $50 \mathrm{ppm}$ of carbon (Fig.4, curve 2) does not depend on the amount of $\mathrm{CW}$, in the investigated range of plastic deformation, because the saturation level of the DESE in iron doped with low concentrations of FIAs can be reached after comparatively small amount of $\mathrm{CW}$. Indeed, the saturation of the Snoek atmosphere by carbon atoms can be obtained with about $1 \mathrm{ppm}$ of carbon for a dislocation density of $10^{7} \mathrm{~cm}^{-2}$.

\section{DISCUSSION}

The relaxation mechanism responsible for the DESE involves the "low-temperature diffusion of FIAs" or rather point defect rearrangement in the stress field of the mobile non-screw $\left(71^{\circ}\right)$ dislocations (4). The motion of a dislocation through a Snoek atmosphere (elastically polarized atmosphere of FIAs in the stress field of a dislocation) leads to the DESE. However, at present stage of investigation the mode of dislocation movement is not precised. Not only is the DESE observed in freshly deformed iron but also the snoek effect, a noticeable increase in the frequency independent IF background, and dislocation pinning. What is particularly disturbing in the investigation of the DESE/C,N/ is that, depending on different experimental conditions and different initial state of the sample (4), the four above mentioned processes can occur simultaneously at different strength.

A detailed discussion on this topic will be published elsewhere (11).

The influence of $\mathrm{CW}$ at $\mathrm{RT}$ on the $\mathrm{DESE} / \mathrm{C} /$ is shown in Fig. 4; a linear stage and the saturation stage can be observed. The linear part was reported by Magalas (7) in $\mathrm{Fe}-\mathrm{C} / 1000 \mathrm{ppm} /$ alloy containing $80 \mathrm{ppm}$ of carbon in solid solution. The saturation phenomenon was observed by Stephenson and Conard (8) in Fe containing 10 $\mathrm{ppm}$ of $\mathrm{C}$ and $10 \mathrm{ppm}$ of $\mathrm{N}$ in solid solution, and also by Magalas after CW of $\mathrm{Fe}-\mathrm{C} / 1000$ / iron which had been aged at $673 \mathrm{~K}$ before deformation (4). After different amounts of plastic deformation, the peak temperature of the DESE/C/ remains constant. Also, the peak height does not depend on the total amount of plastic deformation, which is in contrast to the Snoek-Köster relaxation in bcc metals. As discussed previously $(1,4)$, the enhancement of the Snoek effect is more significant for low concentrations of FIAs. In consequence, the relaxation strength of the DESP is always important in iron doped with low concentrations of FIAs, even in the case of small plastic deformation. According to Ogurtani and Seeger (2), the relaxation strength of the DESE in a homogeneous, diluted alloy, $\mathrm{C}_{0} \ll 1$ should be proportional to the concentration of FIAs in solid solution $C_{0}$. It had previously been mentioned $(1,4)$ that this relationship is not experimentally confirmed. However, the up-dated non-linear theory of the DESE due to Ogurtani and Seeger (12) will take into account the interaction energy between dislocations and FIAs. This theoretical approach should lead to the concept of the saturated Snoek atmosphere and the saturation level of the DESE, as it is experimentally observed in Fe-C alloys, see Fig.4.

It is expected that the Snoek effect due to carbon in solid solution far away from the mobile dislocations can contribute to the IF only in the case of high carbon 
concentrations. The contribution of this part being too small for iron containing low concentrations of carbon atoms. This effect can explain the difference in the saturation level of the DESE/C/ (see Fig.4).

As shown in Fig.1,2,3 the level of IF background is markedly changed in freshly deformed iron. The frequency independent IF background is probably connected with the motion of free dislocations loosely interacting with FIAs. The variation of the IF background due to successive annealings at $305 \mathrm{~K}$ is demonstrated in Fig.3. It can be concluded that the low-temperature annealing caused a decrease of the IF background without any evolution of the relaxation strength of the carbon $\mathrm{DESP} / \mathrm{C} /$.

As already mentioned, virtually the presence of carbon precipitates can modify the contribution of the four, above mentioned, components to the IF. In fact, plastic deformation may cause a dissolution of carbon precipitates and can increase the concentration of FIAs in solid solution. However, the strongest argument in favour of the DESE is that the DESP/C/ is observed in freshly saturated, deformed iron and in deformed iron containing a large amount of carbon precipitates.

It seems clear that the DESE should be a common anelastic relaxation in bcc metals containing heavy FIAs in a similar way to the snoek-Köster relaxation. However, a word of caution is needed, since in the case of $\mathrm{Nb}-0$ it turned out that the oxygen pick-up appeared to modify the oxygen Snoek peak (9). The effect of enhancement of the oxygen Snoek peak in Nb-O was originally interpreted in terms of the influence of plastic deformation or/and annealing treatment (13) on the Snoek effect and led the authors to the idea of the oxygen DESE/O/ in Nb-0 alloys (10,13). Thus, the experimental to-date results for Nb-0 alloys cannot support the notion for the existence of the oxygen $\mathrm{DESE} / \mathrm{O} /$ in $\mathrm{Nb}-0$ alloys doped with comparatively high concentrations of oxygen $1965,930,190,100,70 \mathrm{ppm}(9,10) /$. The results of the influence of plastic deformation on the oxygen Snoek effect in Nb-O alloys should, therefore, be carefully reexamined.

According to the experimental data collected so far for Fe-C and Fe-N alloys, and confirmed in the present paper, the manifestation of the DESE/C,N/ in $\alpha-\mathrm{Fe}$ is indisputable. Furthex work on the carbon DESE/C/ in high purity Fe-C alloys is in progress.

\section{CONCLUSIONS}

Summarizing the experimental results presented in this paper, we find that all the observations are consistent with the concept of the Dislocation-Enhanced Snoek Effect - DESE in iron $(1,4,7)$. The plastic deformation at room temperature causes a transformation of the carbon snoek peak into a broad carbon DESP/C/ occurring at nearly the same temperature as the carbon snoek peak in $\alpha-F e$. It is tentatively suggested that the DESE is due to the movement of non-screw ( $71^{\circ}$ ) dislocations controlled by the snoek-type relaxation of foreign interstitial atoms. The asymmetry and the instability of the carbon DESE/C/ are stated to be explained by the diffusion of carbon atoms. The detalled model of the relaxation mechanism for the $\mathrm{DESE} / \mathrm{C}, \mathrm{N} /$ in iron is under consideration and will be reported later.

Acknowledgement

J. Rubianes is grateful to the Departamento de Educacion del Gobierno Vasco for financial support.

\section{REFERENCES}

(1) Magalas L.B., Gorczyca S., J. de Phys., 46 (1985) C10-253.

(2) Ogurtani T.0., Seeger A., Phys. Rev. B $3 \overline{1}$ (1985) 5044.

(3) Seeger A., J. de Phys., 42 (1981) C5-201.

(4) Magalas L.B., in Internal Friction in Solids, Proc. Summer School on Internal Friction in Solids, June 14-17 Cracow 1984, ed. by S. Gorczyca, L.B. Magalas, Krakow 1984, p.89.

(5) Vanonj F., Thèse de Doctorat, Université Scientifique et Medicale, Grenoble (1973).

(6) Nowick A.S., Berry B.S., Anelastic Relaxation in Crystaline Solids, Academic Press 1972.

(7) Magalas L.B., Moser P., Ritchie I.G., J. de Phys., 44 (1983) C9-645.

(8) Stephenson E.T., Conard II G.P., Acta Met., 16 (1968) 1253. 
(9) Molinas B.J., Weller M., Schulz K., Diehl J., This Conference.

(10) Seeger A., Weller M., Diehl J., Pan Z.I., Zhang J.X., Kë T.S., Z. Metallkde., $73(1982) 1$.

(11) Magalas L.B., to be published.

(12) Ogurtani T.0., private communication.

(13) Melik-Shakhnazarov V.A., Naskidashvili I.A., Serdobintsev. V.I., Fiz. Metal. Metalloved., 40 (1975) 1118.

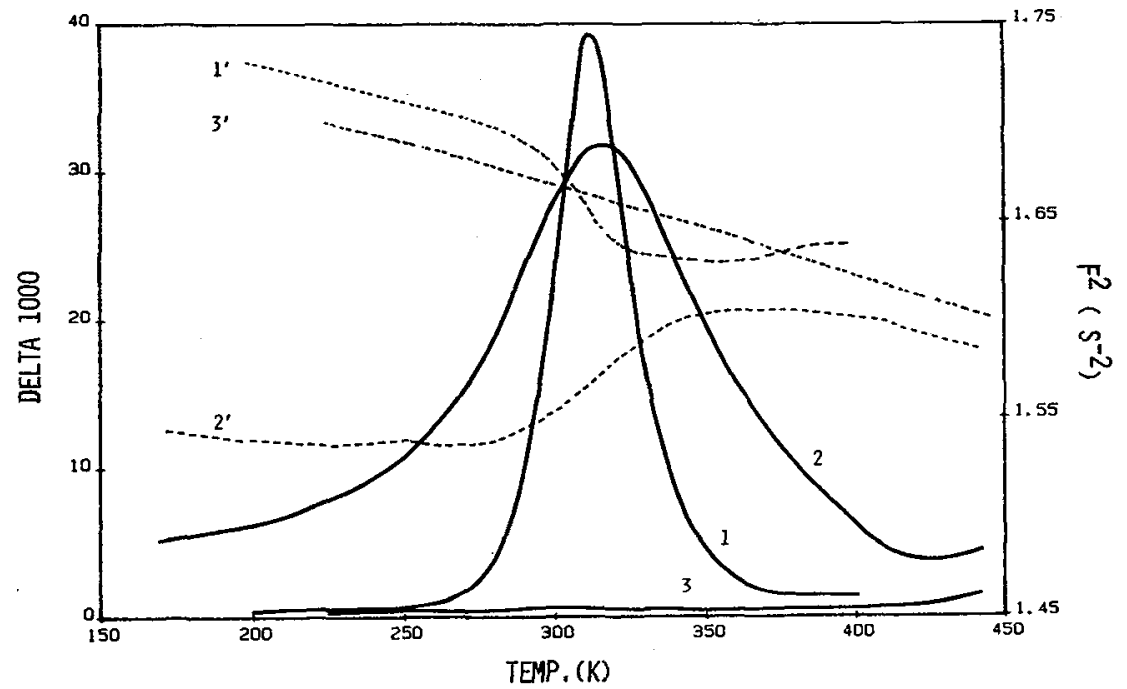

Fig. 1. The carbon Snoek peak in high purity iron doped with 1000 ppm of carbon (sample A) after saturation from $720^{\circ} \mathrm{C}$ (curve $1,1^{\prime}$ ). The carbon DESP/C/ after $14 \% \mathrm{CW}$ at $\mathrm{RT}$ (curve $2,2^{\prime}$ ). IF after annealing at $690 \mathrm{~K}$ (curve $3,3^{\prime}$ ).

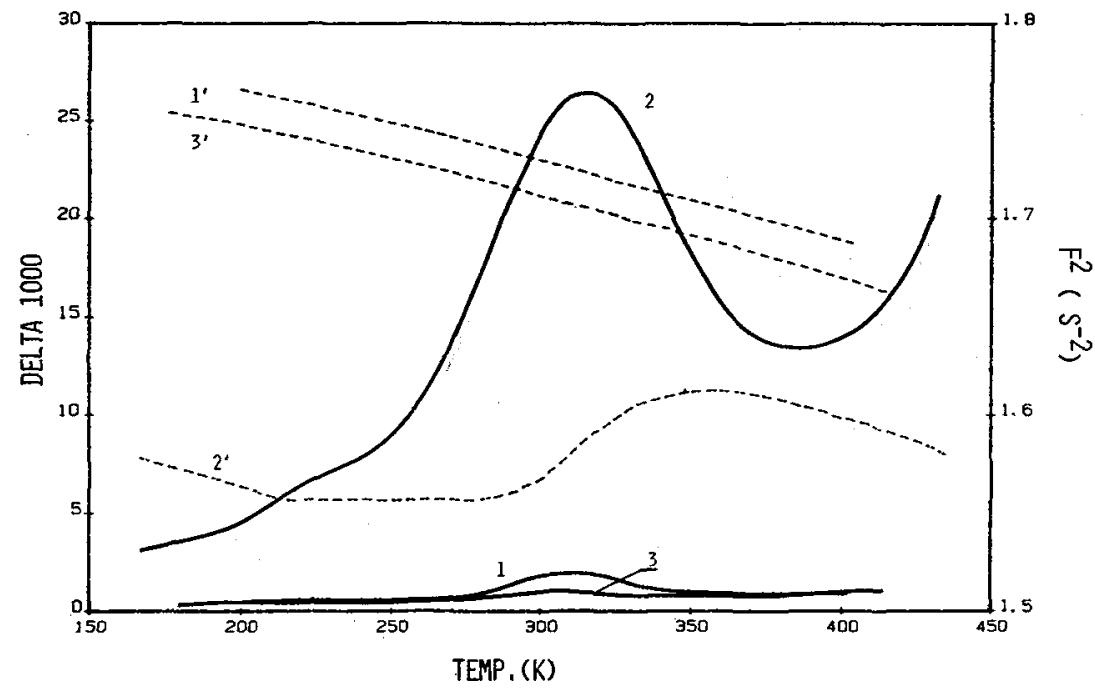

Fig. 2. The carbon Snoek peak in high purity iron doped with 50 ppm of carbon (sample B) after saturation from $720^{\circ} \mathrm{C}$ (curve $1,1^{\prime}$ ). The carbon DESP/C/ after $10 \% \mathrm{CW}$ at $\mathrm{RT}$ (curve $2,2^{\prime}$ ). IF after annealing at $690 \mathrm{~K}$ (curve $3,3^{\prime}$ ). 


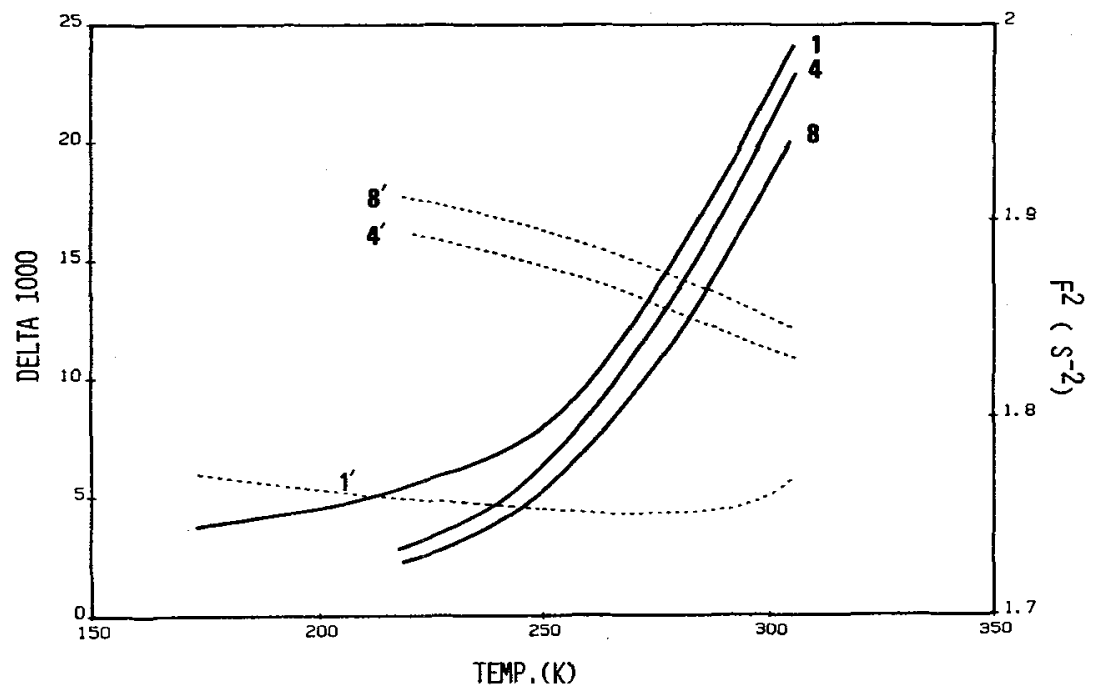

Fig. 3. The influence of successive annealings at $305 \mathrm{~K}$ on the carbon DESP/C/ obtained after $10 \% \mathrm{CW}$ at RT (sample B).

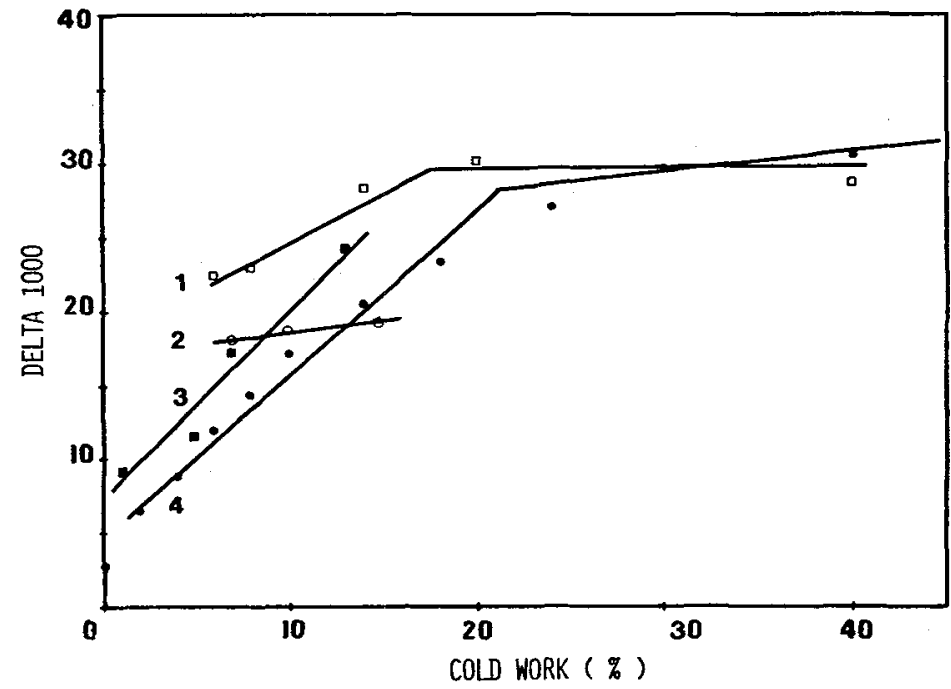

Fig. 4. The evolution of the height of the carbon DESP/C/ with the amount of plastic deformation at RT.

1 : Sample A; high purity iron doped with $1000 \mathrm{ppm} \mathrm{C,} 680 \mathrm{ppm}$ of $\mathrm{C}$ in solid solution.

2 : Sample B; high purity iron doped with $50 \mathrm{ppm} \mathrm{C,} 25 \mathrm{ppm}$ of C in solid solution.

3 : Magalas results (4); high purity iron doped with $1000 \mathrm{ppm} \mathrm{C,} 80 \mathrm{ppm}$ of $\mathrm{C}$ in solid solution.

4 : Stephenson and Conard results (8). 